\title{
International Qualitative Research on Teacher Education: Benefits, Challenges, and Future Directions
}

\begin{abstract}
In this article we explore and discuss the benefits of and the challenges that arise when using qualitative methods to conduct research internationally. We firstly discuss the relationship that writers of qualitative studies have with their readers and the implications of this for writing style. This is then followed by an overview of different aspects of data collection design. Within this section we discuss research that we have conducted, as part of a variety of international projects, using two qualitative approaches: systematic documentary research and interview. We then focus on using interview as a research method. This discussion regarding using interviews is divided into two chapters. Firstly, we discuss issues of access and sampling, then the interview itself and the analysis of interview data. The final sections involve a discussion of ways in which validity and reliability can be contextualised within qualitative studies, and also a discussion on generalisability and the possibility of theory generation. We conclude with sections on ethics and possible future directions for international qualitative studies into teacher education.
\end{abstract}

\section{Keywords:}

international qualitative research, comparative studies, teacher education, research on teacher education and professional development, interviews

1 Faculty of Health, Education and Society, University of Northampton, England. E-MAIL: james.underwood@northampton.ac.uk ORCID: https://orcid.org/0000-0001-9351-2408

2 Faculty of Education, University of Białystok, Poland. E-MAIL: m.kowalczuk@uwb.edu.pl ORCID: https://orcid.org/0000-0001-7531-2947

3 Faculty of Health, Education and Society, University of Northampton, England. E-MAIL: joanne.barrow@northampton.ac.uk 


\section{INTRODUCTION}

For many decades research in education was dominated by positivist paradigms and quantitative approaches. This began to change in the mid- $20^{\text {th }}$ century in the UK and the USA, with increasing speed from the 1960s onwards, although this has been a more recent development in many other countries (Arnove, 2013). As we move further into the 21st century, the use of qualitative approaches has now become a firmly established part of education research cultures in a wide range of countries (Lukenchuk, 2013; Tilley, 2019). These studies have incrementally contributed to a deep understanding of individuals' or groups' experiences of and perspectives on educational systems (Kędzierska \& Mizerek, 2013; Tilley, 2019).

This qualitative turn has also been observed in the field of teacher education. A study into all those papers that have been published in "The European Journal of Teacher Education" since the inception of the journal in 1978 observed that over this period "small-scale studies are prevalent, usually following a qualitative design" (Livingston \& Flores, 2017, p. 553) and "the samples are, in general, small, with some exceptions, focusing, in many papers, on case studies” (p. 553).

At the same time, teacher education has undergone a process of globalization and internationalisation and new contexts for doing qualitative studies have emerged (Adamson, 2012). International comparative research, as a field, has been a relatively more cautious adopter of qualitative approaches. However, there has still been a wide range of qualitative, comparative studies that have been published over a 70 year history (Afdal, 2019). Unusually though within comparative, international research - quantitative research approaches still dominate (Bray, 2014). The authors of this paper are passionate about the possibility of generating new knowledge through qualitative international studies. Therefore, this article explores and discusses the benefits of and the challenges that arise when using qualitative methods to conduct research internationally.

A widely accepted definition for "qualitative international studies" is "any research that transcends national boundaries and/or involves comparing phenomena across two or more geographically macro-social units (e.g., countries, cultures, societies, nations or systems)" (Kosmützky, 2015, p. 356; see also: Afdal, 2019; Nowakowska-Siuta, 2014). However, in this specific paper all examples refer to comparisons between countries.

This article is a personal reflective exploration into the challenges and benefits of using qualitative research into teacher education within international contexts. It emerges from research undertaken collaboratively by the authors of this paper and with other scholars in the field of teacher education, supported by embedded 
references to literature within this field. This paper is intended to contribute to debates on the potential for international qualitative studies. However, this paper should not be viewed as a systematic investigation into international qualitative studies - these are described in a range of research handbooks (Suter, Smith, \& Denman, 2019; Brinkmann \& Kvale, 2015; Hantrais, 2008). It rather aims to serve as a source of reflection and inspiration into the process of doing international qualitative research from the perspective of researchers who have spent some time enjoying its benefits and dealing with its problems. This type of reflective article is indeed, of itself, an illustration of the impact of developments in qualitative research, and of researchers ongoing need to develop voices, methods and approaches that are best suited to their current needs and purposes (Palka, 2010; Lukenchuk, 2013).

In this paper we have gleaned examples from three qualitative studies with an international focus on teacher education in which we served as leaders or members of research teams. These research projects are detailed below.

- Example study 1. This first study was an exploration into how 12 teachers from England and from North Macedonia perceived international communities that they belonged to and into how these perceptions compared. It was titled "Building Communities and Sharing Knowledge: A Study into Teachers Working Together across National Boundaries”. The methods used were documentary analysis and largely unstructured interviews. (Resulting publications from this project include - Underwood \& Joshevska, 2019).

- Study 2. The second study, “The Impact of Doctoral Studies on Teachers as Professionals and their Workplaces”, explored and compared via semi-structured interviews the motivations, perceptions and experiences of 42 Polish and Portuguese teachers undertaking doctoral studies and the impact of this on the teachers' personal and professional lives (see: Kowalczuk-Walędziak et al., 2017). The research team consisted of Polish and Portuguese researchers.

- Study 3. The third study was an exploration and comparison into what motivated 4 Bahraini teachers and 4 teachers from England to engage in teacher networking projects with colleagues in the UK. (Resulting publications from this project included - Underwood, 2017).

In the following sections, we firstly present a broad overview of issues common to all qualitative methods. We then focus on specific issues which arise when designing an international study using one particular qualitative method, namely: interview. At the end, we return to a more general discussion on qualitative research 
and its place in the wider academic discourse. There are therefore seven sections with the following titles:

- the reader-writer relationship in qualitative studies,

- overall qualitative research design,

- the interview process (access and sampling),

- doing and analysing interviews,

- generalisability and theory generation,

- reliability and validity,

- ethics for international qualitative research.

\section{THE READER-WRITER RELATIONSHIP IN QUALITATIVE STUDIES}

Two concepts that are fundamental to justifying and positioning qualitative research are the knowing reader and acknowledged subjectivity. With the small number of participants typically involved in qualitative studies, a question frequently asked by qualitative researchers of themselves and their own research is: how can I be sure my research is objective? To which our answer as mentors of researchers is very simple - that you cannot be. Therefore, qualitative research, or at least small scale qualitative research, must justify its validity and its position in academic debates in other ways. This is because while acknowledging that objectivity is impossible, it is still vital that writers strive for validity.

This validity though is not achieved through objectivity but through openly acknowledging subjectivity, and this often means the writer informing the reader about themselves as a researcher and writer in the early stages of an article or paper. These personalised accounts of the writers' background and relationship to the topic being studied are a distinct aspect of many qualitative papers (Cogni, 2018). Examples can illustrate this better than explanation. A writer on the experiences of Black women in the British education system, according to this paradigm would inform the reader of her own cultural heritage as a young woman of African heritage living in the United Kingdom (Fakile, Underwood, \& Sehr, 2019). Thus they have informed their reader of the subjectivity they may have, enabling the reader to interpret their perspective and respond in an informed way. This approach to achieving validity is challenging within some academic traditions in which validity and objectivity are seen as synonyms. However, it enables qualitative researchers to assert that their research is valid without making unrealistic and unachievable claims of objectivity. 
These concepts of the knowing reader and acknowledged subjectivity then lead to the logical next step being that qualitative research is often written in the first person 'I' or 'we'. This is because the writing that emerges from such research is not claiming to be objective, it is acknowledging that any interpretation is subjective. A subjective interpretation must come from a subject, a single person or a few persons who have interpreted data in a certain way and whose backgrounds and potential biases have been made known to the reader. In this case therefore the use of 'I' or 'we' becomes a philosophical statement placing a writer within a specific paradigm (Smith, 1998). This is why many qualitative researchers choose to use the first person.

The first challenge presented in this article is therefore that it may be challenging for academics from other paradigms to accept and understand qualitative research that is written from an acknowledged subjective perspective (Creswell, 2013). This may especially be the case if presenting to an international audience (Arnove, 2013). You yourself as a reader may have already been challenged by our doing this. However, a benefit of this approach to writing entirely qualitative research is that if approached reflectively and thoughtfully, writers can free themselves from the pressure of striving towards objectivity. Instead they can find a way to define their role in the academic conversation as one that involves generating ideas and possibilities (Rubin \& Rubin, 2012). These may be subjective and based on small numbers of participants but can still be interesting, enlightening and may lead to enriching academic conversations.

\section{OVERALL QUALITATIVE RESEARCH DESIGN}

Researchers may be drawn to qualitative approaches because of their perceptions of the nature of knowledge and the ways in which they want to contribute to the wider academic debate (Lakenchuk, 2013). However, they may also be drawn to using qualitative methods, within a specific project, simply because of the topic that they are studying or because it is a relatively unresearched area requiring initial exploratory research (Yin, 2014). This is illustrated below by a discussion of study one and study two. Although we have used these studies, so as to provide concrete examples, the issues we discuss commonly arise with many qualitative international projects.

In the case of study one (an interview study involving teachers from England and North Macedonia), a significant reason for the decision to construct an entirely qualitative design was that the aims and goals of teacher networking programmes, 
articulated in the literature of the organisations that promote international networking, tend to be strong, clear and hard to disagree with (Underwood, 2017). Therefore, if a quantitative process, with typically a larger number of participants, had been used, there might have been a strong likelihood of gaining data where the participants would replicate each other and where little new understanding would be gained. Qualitative research can be especially valuable when researching into complex areas, with large areas of agreement but where the researcher is interested in subtly different perspectives (Silverman, 2013). This was very much how the author of this study perceived it.

Therefore what was needed was an approach that would, via personal narratives and extended descriptions, reveal subtle differences in teachers' perceptions and in the nature of their experiences. This in turn led to the decision that the second and primary part of the research process could most usefully be in the form of interviews. Interview specifically is often an appropriate method to use when studying a complex and nuanced topic, especially one dealing with a variety of cultural arenas (Rubin \& Rubin, 2012).

Having made the decision to construct an entirely qualitative process, the next stage was to design the entire data collection process. The overall design for data collection for many qualitative studies divides into a series of separate and successive stages (Newby, 2014). These stages are successive because each stage is part of the design process rather than an attempt to triangulate (Silverman, 2014). Mixed methods researchers often use multiple methods concurrently in order to triangulate. They use triangulation in order to verify the accuracy of data and therefore ensure the objectivity and generalisability of a study (Creswell, 2013). However, in this case, as is typical of entirely qualitative designs, the researcher was not striving for a high level of generalisability or for objectivity so triangulation was not needed.

More commonly, qualitative designs are used at exploratory or idea-generating research stages of a developing field and the goal of such studies is to generate debate rather than reach generalisable conclusions (Yin, 2014). This was very much the case with this study. The purpose of using different stages in an entirely qualitative study therefore is typically to inform the research design of the next (Robson \& McCartan, 2016). The stages for this particular research study were as follows:

- Firstly, there was a preparatory stage which involved the writing of a conceptual framework. The purpose of this stage was to build an outline of the concepts that would be used to guide the later stages of data collection. This 
stage involved extensive reading and synthesising from research-based and theory-building literature in the field of professional communities.

- The second stage involved the collection and analysis of documentary data. This was specifically documents produced since 2008 by an organisation called the International Teacher Leadership initiative, including those written by teachers involved in this project. The reason these documents were read was because this was the project that had brought the participants in this study together. It was therefore important to understand this project in more depth before designing the interviews, which would be the main form of data collection. The main purpose of this stage therefore was to inform the design of the final stage of data collection.

- The third and final stage involved conducting ten interviews with two different groups of teachers. The first of these was teachers working in schools in England who were all engaged in some way with the International Teacher Leadership initiative. The second group was teachers working in North Macedonia who were similarly engaged in developments in North Macedonia also based on the International Teacher Leadership initiative. This initiative also linked these two groups together into a shared community.

The second example (study 2) was based on a line of research that places teachers' own perspectives on their professional development in the foreground. This line of research strongly emphasises the need to take seriously what teachers themselves value about their learning, particularly in its new forms and new contexts (Yurkofsky, Blum-Smith, \& Brennan, 2019). As a doctorate is the least researched and the least understood form of teachers' professional development, it emerged that it would be particularly valuable to deeply analyse teachers' voices on this complicated and uniquely challenging experience. There is value in looking at large-scale causal relationships in professional development but for this study, at this stage of research, in this field, the authors felt that a qualitative approach would be more revealing. There is often though a process of qualitative and quantitative studies informing each other in a symbiotic relationship. All the authors of this paper have based qualitative designs in part on ideas generated via quantitative studies that they have read, and have been pleased when quantitative researchers have taken inspiration from their work.

The advantage of such an approach to the study of teachers' experiences of any forms of professional development is mainly that it allows the identification of outcomes of teacher professional development, which are difficult to capture using quantitively generated models. In addition, according to these authors, using 
a quantitative approach would not have enabled the capture of "the multiple pathways by which teachers might gain new knowledge, experiment with new practice, or influence student learning” (Yurkofsky, Blum-Smith, \& Brennan, 2019, p. 2). Thus, designing this study as qualitative research allowed the researchers to seek understandings that go beyond making causal links and enabled them to turn their attention to exploring the teachers' motivations, experiences and perceptions of their $\mathrm{PhD}$ studies and the possible impact of these on their personal and professional development as described by the participants. In other words, such an approach provided an opportunity to explore in a broader and deeper way the nuances associated with teachers' experiences of doctoral education.

As this short section on overall design illustrates: one of the benefits of using qualitative methods when conducting international research is that it is possible to construct designs that give depth and nuance when studying complex areas. It is also possible to design pragmatic approaches to access when a researcher may not be in a country for a long time. However, with such designs there are limitations in terms of the ability of a researcher to reach generalisable conclusions. A researcher designing an entirely qualitative study needs to be mindful of this.

\section{THE INTERVIEW PROCESS (ACCESS AND SAMPLING)}

This section and the next address the process of data collection via one specific and commonly used qualitative method, namely: interview. In the next few paragraphs we discuss the ways that sampling frames can be designed for qualitative studies. Then in the following section, we discuss ways of approaching the interview process itself.

With qualitative studies, and perhaps especially international qualitative studies, there is almost always a pragmatic aspect to the selection of the participants and it is best to simply be honest and open about this fact (Punch \& Oancea, 2014). This pragmatic aspect, often given the label 'convenience sampling' (Bryman, 2016), comes down to which participants the researcher can access. In the case of study one (the one involving North Macedonian and English teachers), for example, the researcher was connected through colleagues to the initiative that these teachers belonged to.

In the case of study two, one of the members of the research team was a supervisor of teachers studying for a $\mathrm{PhD}$ degree, another one was the President of a Foundation that involved practitioners who were interested in developing the relationship between research and practice (also via $\mathrm{PhD}$ studies). 
In the case of study three (the interview study into professional communities in Bahrain), the organisation that facilitated access was the British Council. We use this third study as an illustrative example in the next few paragraphs (Underwood, 2017). With this study there were two other ways in which participants were chosen following from the initial 'convenience sampling' approach mentioned above.

The second part of the sampling process could be defined as 'purposive sampling'. This was sampling bounded by specific, formal criteria or dimensions (Silverman, 2014). This produced a pool of potential participants that could have been approached and with whom an interview could be arranged. These dimensions were that the participants must be teachers in England or Bahrain and must be currently (at the time when the interviews were conducted in 2008) involved with the Connecting Classrooms programme run by the British Council. A further criteria was that all the interviewees must speak English well enough that they could be interviewed without a translator. Although, a translator would also be present in case there was any need for further clarification at any stage. The total sample size was eight, divided into two distinct groups of four given the titles 'Teachers from England' and 'Teachers from Bahrain'.

The final stage in the sampling process, which refined this pool to the final groups of interviewees, was sampling based on the likelihood of a depth of data being created which could be defined as 'theoretical sampling' (Robson \& McCartan, 2016). This involved seeking participants who were likely to generate good detailed interview data, in short: who would speak well (Flick, 2014). Sampling based on such a definition again involves acknowledging subjectivity rather than striving for objectivity.

The small sample of eight participants who were finally selected (all of whom agreed to be interviewed) was realistic in terms of generating a relatively small amount of qualitative data in the form of text that could be analysed in depth. This small sample size would be enough to collectively present (but not represent) an overall view of the topic. The decision to choose a sample selection participants also positions this study within a group of related doctoral research studies conducted over recent years at the University of Cambridge. These studies have all involved a sample of between eight and twelve participants and have primarily involved interview (Bolat, 2013; Creaby, 2013; Teleshaliyev, 2014). This study therefore was positioned within a family of related, qualitative, international studies. When designing small-scale studies this use of precedent, referring to similar studies when explaining your design, can be persuasive and helpful.

There were implications that emerged from the decision to interview these teachers in English as this then limited the potential pool of participants to those 
whose English was effectively fluent. This is a section of the population that is almost always a minority in any country outside the Anglophone world, including in Bahrain. These teachers therefore tended to have similar characteristics in that for the most part they had travelled quite widely and built friendships with colleagues and others from other nations in both formal and informal ways. This is not necessarily representative of the wider population of teachers in either country. Potentially this could, simply by this one commonality of being fluent English speakers, have led to the creation of a sample group that shared other political and social values such as a welcoming perspective on globalisation and associated societal changes (Joshevska \& Kirandziska, 2017). However, the exploratory and narrative nature of this research project meant that it was addressed by acknowledging this when publishing from this study. If the researcher is honest and open, these aspects can add extra dimensions when writing up the study, rather than being problematic.

\section{DOING AND ANALYSING INTERVIEWS}

In this next section we discuss the interviews themselves for all three of the projects already referred to as examples in this article.

In the case of the example studies one and three, all the participants spoke fluent English and the interviews were all held in English. They were held in private and were all one-to-one interviews. However, all the Macedonian and Bahraini participants were accompanied by a translator, who was able to clarify phrases or words as required. Conducting all the interviews in the same language is the simplest approach to conducting interviews in an international context but it does bring issues that the researcher at the very least needs to be aware of and needs to show understanding of in their later writing. Fluent second language speakers may be a distinct sub-group in any society with a set of shared values, as discussed above (Underwood, 2017). Also, if a translator is used to assist, then the translator may add another voice and perspective into the interview, even inadvertently (Squires, 2009).

Another approach could be to interview in first languages, then translate into English. The challenge then becomes one of maintaining the accuracy of meaning when translating into English (Squires, 2009). This was exactly the approach adopted for study two. In this case, the interviews were conducted in Polish and later translated into English. This adds an extra element of complexity because there is a need to ensure that a translation retains depth of meaning. This was 
achieved through the involvement of further colleagues who checked all translations and by the close analysis by multiple researchers of significant quotations that would be used in later English language publications.

The interview schedule and process for studies one and three was as follows. As a prompt to enable the participants to start talking freely, they were asked to draw a diagram of the different professional communities that they belong to and to discuss and explain their diagram. They were told they could draw this in any way they wished. Following this, a conversation took place based on a very simple interview schedule. This schedule consisted of just a small number of prescheduled themes from which further discussion developed. The same interview schedule was used with all the participants with an expectation that all would potentially contribute data that would be useful for answering all the research questions.

This simple design for a qualitative interview is effective in an international context because the design needs to be culturally sensitive to potentially very different educational, social and political cultures. A largely unstructured interview design such as this allows the participants to expand upon their answers freely while having more control over the interview, including being able to steer it away from sensitive topics.

At the heart of the process of data analysis for any qualitative study is the iterative generation of a framework of themes that eventually build towards the findings and conclusions of the study. These are often - in methods books - given the technical name of categories each underpinned by a series of codes, and there are extensive texts on ways of systematically approaching the recording of these (Charmaz, 2014; Birks \& Mills, 2015). However, even when these are unwritten thoughts in the researchers' mind, the process of identifying and refining themes that help the researcher and future readers to understand the research topic is at the heart of qualitative research.

For all the example studies referred to in this paper, the authors first researched and wrote an initial conceptual framework based on reading widely that gave a framework for the later analysis of documents and interview data. In study one, a further analysis of documents that had been produced from within the International Teacher Leadership initiative refined this framework further. In all the example studies, the main and last form of data collection was interview. The interviews were analysed in the context of the framework that had been already written prior to analysis' beginning. However, during this process of analysing, the interviews' new themes emerged. 


\section{GENERALISABILITY AND THEORY GENERATION}

So far in this article we have discussed our approach to conducting qualitative research in an international context. However, the biggest challenge faced by many qualitative researchers is not how to do the research, but how to position their research. World-wide there are a range of different perspectives on small-scale, qualitative research and while very few places are hostile, it is still an emerging aspect of mainstream academic discourse in some countries. Therefore in these next two sections to this article we discuss the possibilities and challenges when generating theory and making claims for validity, reliability and generalisability with qualitative research. There is also a final section on the distinct ethical challenges posed when conducting qualitative research.

When asserting claims for qualitative research, the precedent of other researchers is often a good starting point as it can ground a study in wider academic debates. There is one, perhaps now slightly dated, view on qualitative research which is that small-scale qualitative studies can tell interesting stories about specific cases but should avoid any more generalised claims as the sample size is often too small (Silverman, 2014). There is some strength to this view, and interesting individual stories certainly have a place in academic debate. However, a rival view is that it is also possible for qualitative studies to make more generalisable claims and to generate theories as long as this is done in a thoughtful and nuanced way (Rubin \& Rubin, 2012).

For qualitative researchers, one simple and useful definition of what it means to generate a theory from research is that a theory is any statement that potentially forms an explanatory definition for a phenomena (Rubin \& Rubin, 2012). This definition is less rigid in the depth of data that is required before a researcher makes a theoretical statement based on their research. It is useful because it fits with a discourse of research written from a perspective of acknowledged subjectivity. Using this definition the validity of qualitative studies can be justified by their contribution to wider debates rather than because of the possibility for generalisability based on a high degree of certainty (Silverman, 2014).

According to this definition of theory generation, the writers of even smallscale qualitative studies should be bold enough to attempt to suggest potential propositions that could be more broadly applicable, rather than simply telling the story of the individual case (Yin, 2014). By framing the theories that their smallscale qualitative study has generated in nuanced terms, there is the possibility, for writers, of generating an innovative and significant contribution to academic debate even from a small-scale qualitative study. 


\section{RELIABILITY AND VALIDITY}

The extent to which it is possible to claim that qualitative research is either reliable or valid also depends in part on how these contested terms are defined. As with generalisability there is a more cautious definition of reliability, commonly used in much quantitative research, by which 'reliability' is defined as a near synonym with 'repeatability' (Flick, 2014). According to this definition, it is impossible for small-scale research to be reliable. This is largely because with small numbers of participants, even if a study were to be repeated, it would be unlikely that precisely the same results would emerge. It may be that some conclusions would remain the same but this is not the same as replicating every result of the study. However, there are other approaches to the definition of reliability that are more suitable to qualitative studies. One alternative way in which this can be defined is by the consistent application of a method, albeit accepting that some methods have pre-designed flexibility and also by the researcher maintaining a thorough audit trail (Bryman, 2016). With this definition, a closer synonym than 'repeatability' to 'reliability' for qualitative research is ‘dependability'.

Similarly, claims for validity with qualitative studies can be defined and explained better by using concepts such as: honesty, rigour, and systematicness. To understand this better, a useful comparison is with historical research rather than with the sciences. A historian interviewing those who fought at a famous battle many decades later is unlikely to interview all the veterans of this battle. Instead she might interview some and from their stories might construct a picture of events and of how these soldiers felt and behaved at the time. If another historian were to replicate this study, they would not expect to hear exactly the same answers. However, both historians would expect there to be some commonalities in what was said. They would also both expect that the other researcher kept all their notes and transcripts, have interpreted them in a systematic way and certainly has been truthful at every stage of research and writing. If this definition of validity is used then qualitative researchers in education, just like historians, can make statements and build theories that go beyond reporting specific cases and can still make claims for validity.

Another way in which the design of a qualitative study can make claims for validity is by ensuring dialogue with participants. This might for instance be by sending participants a short summary of key findings likely to appear in any publication (Charmaz, 2014). By doing this, a writer can be more confident that the final publications that emerge from a study are a true reflection of the experiences and perceptions of the participants. At this stage, especially with an international research study, participants might clarify cultural issues or explain or challenge 
interpretations. This is also a way of showing respect to participants as interviewees may have consented to the collection of data, via interview, but this does not necessarily mean that they have agreed to the accompanying process of extraction, selection and interpretation that is the next stage of research. However, designing this element of consultation into a study also needs to have clear limits. It is reasonable to consult participants on key findings once or twice but this should not become an endless process or be allowed to interfere with the integrity of the researcher to reach their own conclusions (Robson \& McCartan, 2016).

In conclusion to these two sections, there is a live and vigorous debate regarding the possibility for theory generation from qualitative studies. Similarly, there is also ongoing debate regarding the possibility for qualitive studies to make claims for validity and reliability. However, the qualitative researcher can use the precedent of others to make such claims as long as they are cautious with the arguments with which this is expressed.

\section{ETHICS FOR INTERNATIONAL QUALITATIVE RESEARCH}

In this final section we discuss ethical issues that can arise when conducting international qualitative research. For this section we return to 'example: study one' specifically in order to provide illustration. By discussing at each stage the ethical decisions that the author of this study made, more general issues about research ethics with qualitative international studies have also been discussed below.

The overall design of this study was low risk in terms of the ethical issues that arose. However, with all studies it is still important to minimise any potential harm. With this study, the process of minimising the risk of causing harm began with the design of the document collection stage. The pool that the documents were selected from consisted entirely of documents that had already been released into the public domain. Therefore there was no risk of documents that had originally been written in a confidential capacity causing any form of harm by being discussed openly. Next, the participants who were selected were all highly qualified professionals. Much education research involves children and whilst this can be very valuable, it is easy for researchers in this field to ignore the potential of research that solely investigates the experiences of teachers or other education professionals. This is not an ethical issue in and of itself as it is possible to conduct ethically sound research with children. However, by choosing to focus on educated adults, this can mean that it is easier to design a lower risk study and to gain access especially in international contexts that require a high degree of sensitivity. 
When it came to the interviews themselves, at the start of each interview, the participants were fully informed of the nature and purpose of the interviews along with their rights. This included the principle of informed consent and their right to withdraw from contributing to this study at any stage (BERA, 2018). The interviewer asked permission for the interviews to be recorded and later transcribed and explained that these recordings and transcriptions would be securely stored until the completion of this study. Finally, the participants were also assured of anonymity during the process of writing up these interviews.

Ethics, however, is not only about the processes of keeping participants informed. It is also about the design of the study itself (Rubin \& Rubin, 2012). A researcher should be mindful of their relationship to the participants and this may especially be the case in countries with more hierarchical cultures or greater power distance. As an interviewer, the researcher of this study, planned to be empathetic and uncritical and for the interviews to be a professional conversation between two people of equal standing and expertise - the researcher and the teacher. In order to ensure that this was the case, the interviewer did not simply ask questions but rather allowed the teachers to discuss freely, occasionally prompting them to gain more information or clarity. The questions that were asked were clear and related to the theme of the research, which the participants were already aware of.

If participants wished to pursue an explanatory line or a narrative they were given the space to talk freely, and similarly, if any issues were ones that they did not want to discuss it was fine for them to avoid that topic. In all instances the interviews were conducted in a comfortable environment and with the North Macedonian interviewees a bilingual translator was able to ensure that the teachers could feel confident that subtleties in meaning were accurately put forward. Thus even in the detail of the environment there was an implied respect for the participants, their generosity in giving up their time and for sharing their understanding and expertise.

In conclusion to this section, research ethics is consistent across all education research. However, it is especially important that international studies are designed so that they avoid any potential harm. It is also important that cultural awareness and sensitivity are parts of the design of international qualitative studies.

\section{CONCLUSION AND FUTURE DIRECTIONS}

The purpose of this paper was to explore and discuss the benefits of and the challenges that arise when using qualitative methods to conduct research internationally. Although this paper should not be considered a systematic investigation into 
international qualitative studies, it provides some interesting reflections on the benefits and challenges of qualitative research, especially when interviews are used for data collection. As far as benefits are concerned, this paper suggests that international qualitative studies are beneficial for generating new knowledge and insights into complex and internationally important issues that cannot be fully understood via quantitative studies. These might be studies into relatively unexplored areas, or they may be studies that are positioned within culturally sensitive contexts. They may also be studies where the nature of exactly what is being compared is in itself a topic of the research - whether for example it be practice or perception or societal context. Although the three example studies were very different, the need for nuanced understanding within a complex, cultural environment was common to all. With all these studies, the use of qualitative approaches enabled exploration in depth and also facilitated cultural sensitivity and thus access to participants.

Bearing in mind the internationalisation and globalization of teacher education processes, further international qualitative studies will continue to be essential vehicles for exploring new contexts, new cross-cultural phenomena and for approaching complex areas with sensitivity. With the development of technology that continues to bring teachers together and changes the nature of teaching communities and the sharing of knowledge, we expect the number and range of qualitative international comparative studies to grow; the definition of comparative to be continually explored and challenged, and the range of qualitative approaches to diversify. This paper has presented our reflections upon this exciting and developing field. We look forward positively as these debates grow, reframe and develop.

\section{References}

Adamson, B. (2012). International Comparative Studies in Teaching and Teacher Education. Teaching and Teacher Education, 28(5), pp. 641-648. DOI: 10.1016/j.tate.2012.02.003.

Afdal, H.W. (2019). The Promises and Limitations of International Comparative Research on Teacher Education. European Journal of Teacher Education, 42(2), pp. 258-275. DOI: 10.1080/02619768.2019.1566316.

Arnove, R. (2013). Introduction: Reframing Comparative Education: The Dialectic of the Global and the Local. In: R. Arnove, C.A. Torres, \& S. Franz (Eds.), Comparative Education: The Dialectic of the Global and the Local (4 ${ }^{\text {th }}$ Ed.) (pp. 1-27). London, UK: Rowman \& Littlefield.

Birks, M., \& Mills, J. (2015). Grounded Theory: A Practical Guide. London, UK: Sage.

Bolat, O. (2013). A Non-Positional Teacher Leadership Approach to School Improvement: An Action Research Study in Turkey. Unpublished doctoral dissertation. University of Cambridge. 
Bray, M. (2014). Actors and Purposes in Comparative Education. In: B. Adamson, M. Bray, \& M. Mason (Eds.), Comparative Education Research: Approaches and Methods ( $2^{\text {nd }}$ Ed.) (pp. 19-46). Hong Kong: University of Hong Kong Press.

Brinkmann, S., \& Kvale, S. (2015). InterViews: Learning the Craft of Qualitative Research Interviewing ( ${ }^{\text {rd }}$ Ed.). Thousand Oaks, CA: Sage.

The British Education Research Association (BERA) (2018). Revised Ethical Guidelines for Educational Research. UK: BERA. Retrieved from: http://www.bbk.ac.uk/sshp/research/ sshp-ethics-committee-and-procedures/BERA-Ethical-Guidelines-2011.pdf.

Bryman, A. (2016). Social Research Methods ( $5^{\text {th }}$ Ed.). Oxford, UK: Oxford University Press. Charmaz, K. (2014). Constructing Grounded Theory ( $2^{\text {nd }}$ Ed.). London, UK: Sage.

Cogni, M. (2018). From Sentences to Essays: A Guide to Reflective Writing through Reflective Thinking. USA. Vernon.

Creaby, C. (2013, September). Teacher Identity and Implications for Educational Improvement. Paper presented at the European Conference on Education Research (ECER) 2013. Istanbul, Turkey.

Creswell, J.W. (2013). Qualitative Inquiry \& Research Design: Choosing among Five Approaches ( $3^{\text {rd }}$ Ed.). Thousand Oaks, CA: Sage.

Fakile, D., Underwood, J., \& Sehr, R. (2019, June). Is My University White? 'Tackling Inequalities’ Conference, Keele University. DOI: 10.13140/RG.2.2.28334.66888.

Flick, U. (2014). An Introduction to Qualitative Research (5 ${ }^{\text {th }}$ Ed.). London, UK: Sage.

Hantrais, L. (2008). International Comparative Research: Theory, Methods and Practice. UK. Palgrave.

Joshevska, M., \& Kirandziska, S. (2017). The Rise and Rise of Teacher Leadership in Macedonia. In: D. Frost (Ed.), Empowering Teachers as Agents of Change: A Non-Positional Approach to Teacher Leadership (pp. 79-84). Cambridge, UK: Cambridge University Press.

Kędzierska, H., \& Mizerek, H. (Eds.) (2013). Jakościowe inspiracje w badaniach edukacyjnych refleksje na marginesie projektów badawczych. Olsztyn: Wydawnictwo UWM.

Kosmützky, A. (2015). In Defence of International Comparative Studies. On the Analytical and Explanatory Power of the Nation State in International Comparative Higher Education Research. European Journal of Higher Education, 5(4), pp. 354-370. DOI: 10.1080/ 21568235.2015.1015107.

Kowalczuk-Walędziak, M., Lopes, A., Menezes, I., \& Tormenta, N. (2017). Teachers Pursuing a Doctoral Degree: Motivations and Perceived Impact. Educational Research, 59(3), pp. 335-352. DOI: 10.1080/00131881.2017.1345287.

Livingston, K., \& Flores, M.A. (2017). Trends in Teacher Education: A Review of Papers Published in the European Journal of Teacher Education over 40 Years. European Journal of Teacher Education, 40(5), pp. 551-560. DOI: 10.1080/02619768.2017.1387970.

Lukenchuk, A. (Ed.) (2013). Paradigms of Research for the $21^{\text {st }}$ Century: Perspectives and Examples from Practice. Oxford: Peter Lang.

Newby, P. (2014). Research Methods for Education ( $2^{\text {nd }}$ Ed.). Abingdon, UK: Routledge.

Nowakowska-Siuta, R. (2014). Pedagogika porównawcza. Problemy, stan badań i perspektywy rozwoju. Kraków: Oficyna Wydawnicza Impuls.

Palka, S. (Ed.) (2010). Podstawy metodologii badań w pedagogice. Gdańsk: GWP. 
Punch, K., \& Oancea, A. (2014). Introduction to Research Methods in Education (2 ${ }^{\text {nd }}$ Ed.). London, UK: Sage.

Robson, C., \& McCartan, K. (2016). Real World Research (4 ${ }^{\text {th }}$ Ed.). Chichester, UK: Wiley.

Rubin, H., \& Rubin, I. (2012). Qualitative Interviewing: The Art of Hearing Data ( $3^{\text {rd }}$ Ed.). London, UK: Sage.

Silverman, D. (2013). Doing Qualitative Research (4 ${ }^{\text {th }}$ Ed.). London, UK: Sage.

Silverman, D. (2014). Interpreting Qualitative Data (5 ${ }^{\text {th }}$ Ed.). London, UK: Sage.

Smith, M.J. (1998). Social Science in Question. London, UK: Sage.

Squires, A. (2009). Methodological Challenges in Cross-Language Qualitative Research: A Research Review. International Journal of Nursing Studies, 46(2), pp. 277-287. DOI: 10.1016/j.ijnurstu.2008.08.006.

Suter, L., Smith, E., \& Denman, B. (2019). The SAGE Handbook of Comparative Studies in Education. London, UK: Sage.

Tilley, S. (2019). The Role of Critical Qualitative Research in Educational Contexts: A Canadian Perspective. Educar em Revista, 35(75), pp. 155-180. DOI: 10.1590/0104-4060.66806.

Teleshaliyev, N. (2014, September). Teachers with a Capital ' $T$ ' in Kyrgyzstan: Moral Purpose, Self-efficacy and Resilience. Paper Presented at the European Conference on Education Research (ECER) 2014. Porto, Portugal.

Underwood, J. (2017, September). Exchanging Knowledge and Building Communities via International Networking. The Asian Conference on Education and International Development, Kobe Arts Centre, Kobe, Japan.

Underwood, J., \& Joshevska, M. (2019). A Proposed Typology of Knowledge Sharing within Communities of Teachers: A Comparative Case Study Focusing on England and Macedonia. IAFOR Journal of Education, 7(1), pp. 113-128. DOI: 10.22492/ije.7.1.07.

Yin, R. (2014). Case Study Research: Design and Methods (5 ${ }^{\text {th }}$ Ed.). London, UK: Sage.

Yurkofsky, M., Blum-Smith, S., \& Brennan, K. (2019). Expanding Outcomes: Exploring Varied Conceptions of Teacher Learning in an Online Professional Development Experience. Teaching and Teacher Education, 82, pp. 1-13. DOI: 10.1016/j.tate.2019.03.002. 